\title{
Immunization against a Conserved Surface Polysaccharide Stimulates Bovine Antibodies with Opsonic Killing Activity but Does Not Protect against Babesia bovis Challenge
}

\author{
Naomi S. Taus ${ }^{1, * \mathbb{D}}$, Colette Cywes-Bentley ${ }^{2}$, Wendell C. Johnson ${ }^{1}$, Gerald B. Pier ${ }^{2}$, Lindsay M. Fry ${ }^{1,3}$, \\ Michelle R. Mousel ${ }^{1,4}$ and Massaro W. Ueti ${ }^{1,3,4}$ \\ 1 Animal Disease Research Unit, Agricultural Research Service, U.S. Department of Agriculture, \\ Pullman, WA 99164, USA; carl.johnson@usda.gov (W.C.J.); lindsay.fry@usda.gov (L.M.F.); \\ michelle.mousel@usda.gov (M.R.M.); massaro.ueti@usda.gov (M.W.U.) \\ 2 Division of Infectious Diseases, Department of Medicine, Brigham and Women's Hospital, Harvard Medical \\ School, Boston, MA 02115, USA; ccywes@rics.bwh.harvard.edu (C.C.-B.); gpier@bwh.harvard.edu (G.B.P.) \\ 3 Program in Vector-Borne Diseases, Department of Veterinary Microbiology and Pathology, \\ Pullman, WA 99164, USA \\ 4 Paul G. Allen School for Global Animal Health, Washington State University, Pullman, WA 99164, USA \\ * Correspondence: naomi.taus@usda.gov; Tel.: +(509)-335-6318; Fax: +(509)-335-8328
}

Citation: Taus, N.S.; Cywes-Bentley, C.; Johnson, W.C.; Pier, G.B.; Fry, L.M.; Mousel, M.R.; Ueti, M.W. Immunization against a Conserved Surface Polysaccharide Stimulates Bovine Antibodies with Opsonic Killing Activity but Does Not Protect against Babesia bovis Challenge. Pathogens 2021, 10, 1598. https:// doi.org/10.3390/pathogens10121598

Academic Editor: Marcello Otake Sato

Received: 4 November 2021

Accepted: 7 December 2021

Published: 9 December 2021

Publisher's Note: MDPI stays neutral with regard to jurisdictional claims in published maps and institutional affiliations.

Copyright: (c) 2021 by the authors. Licensee MDPI, Basel, Switzerland. This article is an open access article distributed under the terms and conditions of the Creative Commons Attribution (CC BY) license (https:// creativecommons.org/licenses/by/ $4.0 /)$.

\begin{abstract}
Arthropod-borne apicomplexan pathogens remain a great concern and challenge for disease control in animals and humans. In order to prevent Babesia infection, the discovery of antigens that elicit protective immunity is essential to establish approaches to stop disease dissemination. In this study, we determined that poly-N-acetylglucosamine (PNAG) is conserved among tick-borne pathogens including B. bovis, B. bigemina, B. divergens, B. microti, and Babesia WA1. Calves immunized with synthetic $\beta-(1 \rightarrow 6)$-linked glucosamine oligosaccharides conjugated to tetanus toxoid $\left(5 \mathrm{GlCNH}_{2}-\right.$ TT) developed antibodies with in vitro opsonophagocytic activity against Staphylococcus aureus. Sera from immunized calves reacted to $B$. bovis. These results suggest strong immune responses against PNAG. However, $5 \mathrm{GlCNH}_{2}$-TT-immunized bovines challenged with $B$. bovis developed acute babesiosis with the cytoadhesion of infected erythrocytes to brain capillary vessels. While this antigen elicited antibodies that did not prevent disease, we are continuing to explore other antigens that may mitigate these vector-borne diseases for the cattle industry.
\end{abstract}

Keywords: Babesia; Rhipicephalus ticks; PNAG; immunization; antibody response

\section{Introduction}

Infection with tick-borne apicomplexan parasites such as Babesia spp. has a negative impact on animal and human health worldwide. The parasites are transmitted by infected ticks during their blood meal and then invade and replicate exclusively in the erythrocytes of the mammalian host (reviewed in [1,2]). Following development of the parasites to merozoites, infected erythrocytes lyse and release the merozoites, which continue the cycle by invading uninfected erythrocytes (reviewed in [1,2]). Without a protective immune response, the mammalian host suffers severe babesiosis, which is characterized by high fever, hemolytic anemia, anorexia, cachexia, hemoglobinuria, icterus, and, in some cases, death [3]. Mammalian hosts that survive acute infection become persistently infected for life and are reservoirs from which the biological vector can acquire the parasite and can subsequently transmit it to naïve hosts, as reviewed in [4].

In particular, Babesia bovis causes significant economic losses for livestock producers in tropical and subtropical regions because both the pathogen and its tick vector, Rhipicephalus microplus, are endemic. Preventive strategies for bovine babesiosis caused by $B$. bovis in these endemic regions are limited to the use of live attenuated vaccines and acaricides $[1,5,6]$. Drawbacks to these methods include well-recognized problems with the 
use of live attenuated vaccines such as possible reversion to virulence, the transmission of contaminating blood-borne pathogens, the need for a well-controlled cold chain to preserve vaccine viability, and induction of severe disease and death in cattle older than 6-9 months of age [4-8]. The emergence of $R$. microplus populations that are resistant to multiple acaricides as well as potential problems with environmental contamination from acaricides is also problematic [5]. Therefore, the identification of protective antigens for use in subunit vaccines is a priority for the field.

Recent work has demonstrated that a conserved polysaccharide, poly- $\mathrm{N}$-acetylglucosamine (PNAG), is present on bacteria, viruses, and protozoan parasites and is hypothesized to be a potential antigen for a universal vaccine $[9,10]$. Natural IgG antibodies against PNAG are found in human and animal sera; however, these antibodies poorly activate the complement system and thus are not usually protective against infection [11-13]. However, immunization with PNAG that has been modified by reducing the acetylation of the glucosamine monosaccharides (dPNAG) or synthetic $ß-(1 \rightarrow 6)$-linked glucosamine oligosaccharides conjugated to tetanus toxoid both induce antibodies that fix complement, have antimicrobial killing activity, and provide protective immunity $[9,14]$. Of particular interest was the finding that mice infused with polyclonal antibodies raised against a synthetic $B-(1 \rightarrow 6)$-linked glucosamine oligosaccharide conjugated with tetanus toxoid $\left(9 \mathrm{GlcNH}_{2}-\mathrm{TT}\right)$ and challenged with virulent Plasmodium parasites failed to develop cerebral disease, which is also a feature of bovine babesiosis caused by B. bovis; these mice also lived longer than the controls [9]. These results suggest that PNAG could be used as a target in a vaccine to prevent disease caused by B. bovis and possibly other Babesia spp. In this study, we examined several Babesia spp for the expression of PNAG and tested whether the immunization of calves against PNAG resulted in protection from clinical babesiosis caused by challenge with a virulent strain of B. bovis.

\section{Materials and Methods}

\subsection{Immunofluorescence Assays}

Direct immunofluorescence was used to demonstrate the presence of PNAG on various Babesia spp. Archived thin blood smear slides that were prepared as described in [15] and stored at $-80^{\circ} \mathrm{C}$ at the Animal Disease Research Unit, Agricultural Research Service, United States Department of Agriculture, Pullman, WA, USA, of B. bovis Texas [16], B. bovis Australia [17], B. bigemina Mexico [18], B. divergens [19,20], B. microti [21], and Babesia WA1 [21] were used for the assay. Slides were probed with IgG1 Alexa Fluor 488 conjugated fully human IgG1 monoclonal antibodies specific for PNAG (F598) or Pseudomonas aeruginosa alginate (F429) [11,22] at a concentration of $5.2 \mu \mathrm{g} / \mathrm{mL}$ for $4 \mathrm{~h}$ at room temperature (RT). SYTO 83 orange fluorescent nucleic acid stain (Molecular Probes) diluted to $500 \mathrm{nM}$ in $0.5 \%$ bovine serum albumin in phosphate-buffered saline (BSA in PBS) with a $\mathrm{pH}$ of 7.4 was added to the slides without washing for the final 15 min in order to localize the parasite nuclei. The blood smears were washed, mounted with a coverslip, and antibody reactivity was visualized using confocal microscopy [9].

Indirect immunofluorescence was used to demonstrate that the sera from calves who had been immunized with $5 \mathrm{GlcNH}_{2}-\mathrm{TT}$, a synthetic $\beta-(1 \rightarrow 6)$-linked glucosamine oligosaccharide conjugated to a tetanus toxoid, reacted with $B$. bovis. Thin smears of infected $B$. bovis red blood cells were prepared from the cultures. Slides were incubated with a 1:100 dilution of the pre- or post- immunization sera from either the control (C1587, C1588, C1598) or from the 5GlcNH 2 -TT-immunized calves (C1590, C1594, C1595) for $4 \mathrm{~h}$ at RT. A secondary FITC conjugated (Bethyl A10-102F) rabbit anti-bovine IgG (H+L) antibody was added to the experimental samples at a 1:100 dilution for $2 \mathrm{~h}$ at RT along with $500 \mathrm{nM}$ of SYTO 83 that had been added without washing for the last $15 \mathrm{~min}$ at RT in $0.5 \% \mathrm{BSA} / \mathrm{PBS}$ $\mathrm{pH}$ 7.4. Samples were prepared as described above for confocal microscopy. 


\subsection{Pathogen and Animals}

The highly transmissible Texas strain of $B$. bovis $\left(\mathrm{T}_{2} \mathrm{Bo}\right)$ was used in this study. This parasite strain originated from a quarantined animal in Texas [16]. Six seven-month-old Holstein steers were used in this study and were determined to be B. bovis free by serology and PCR targeting of the rhoptry-associated protein 1 (RAP-1) and rap-1 gene, respectively, as previously described $[23,24]$.

\subsection{Immunization}

Calves received three intramuscular injections using $11 / 2$ in needles in the left side of the neck approximately 21 days apart, at days 0,21 , and 49 , with either $5 \mathrm{GlcNH}_{2}-\mathrm{TT}$ plus adjuvant or adjuvant alone. The immunized group received $200 \mu \mathrm{g}$ of $5 \mathrm{GlcNH}_{2}-\mathrm{TT}$ (AV0328 from Alopexx Vaccine, LLC, Concord, MA, USA) in PBS plus $0.1 \mathrm{~mL}$ of Montanide Pet Gel A per injection (SEPPIC, Inc, Courbevoie, France). The adjuvant group received $0.1 \mathrm{~mL}$ Montanide Pet Gel A adjuvant diluted in PBS per injection. Montanide adjuvant was used because in a preliminary experiment, a calf who had been immunized with $5 \mathrm{GlcNH}_{2}-\mathrm{TT}$ and the adjuvant Specol (Thermo-Fisher Scientific, Waltham, MA, USA) failed to develop antibodies with in vitro opsonophagocytic activity (data not shown). Blood was collected prior to each immunization, and samples stored at $-20^{\circ} \mathrm{C}$.

\subsection{Enzyme-Linked Immunosorbent Assay}

Total antibody titer was determined by PNAG-ELISA using sera from calves who had been immunized with either $5 \mathrm{GlcNH}_{2}$-TT or adjuvant alone. PNAG was isolated from Acinetobacter baumannii, as described in [25]. The optimization of the ELISA encompassed checkerboard titrations of PNAG and monoclonal antibody F598 to PNAG to determine the amount of PNAG that was needed to coat the ELISA plate in order to obtain maximal OD405 $\mathrm{nm}$ readings [11].

In brief, PNAG $(0.6 \mu \mathrm{g} / \mathrm{mL})$ was diluted in $0.04 \mathrm{M} \mathrm{NaH}_{2} \mathrm{PO}_{4}$ and $0.04 \mathrm{M} \mathrm{Na}_{2} \mathrm{HPO}_{4}$, which had a $\mathrm{pH}$ of 7.2, that had been added to the wells of Immulon 4 ELISA plates (Fisher, Hampton, NH, USA), and the samples were incubated overnight at $4{ }^{\circ} \mathrm{C}$. The plates were washed three times with PBS containing 0.05\% Tween 20 (wash buffer). The antigen-coated plates were blocked with PBS plus $2.5 \%$ bovine serum albumin for $1 \mathrm{~h}$ at $37^{\circ} \mathrm{C}$. PBS containing $1 \%$ BSA and $0.05 \%$ Tween 20 (dilution buffer) was used to dilute all of the sera. To determine antibody titer, pre- and post-immunization sera from immunized or adjuvant groups were diluted 1:100 with subsequent two-fold dilutions. Diluted sera were added to the wells and were incubated for $1 \mathrm{~h}$ at $37^{\circ} \mathrm{C}$. Plates were washed three times with wash buffer, and a 1:5000 dilution of alkaline phosphatase-conjugated rabbit anti-bovine IgG in dilution buffer was added and incubated for $1 \mathrm{~h}$ at RT. Plates were washed as before, a 4-nitrophenyl phosphate disodium salt hexahydrate tablet (Sigma) was dissolved in $15 \mathrm{~mL}$ of $20 \mathrm{mM} \mathrm{NaHCO}_{3}, 28 \mathrm{mM} \mathrm{Na}_{2} \mathrm{CO}_{3}$, and $1 \mathrm{mM} \mathrm{MgCl}_{2}$ (substrate buffer), and this was then added to the wells. The plates were incubated in the dark for $1 \mathrm{~h}$ at $37^{\circ} \mathrm{C}$, and the optical density (OD) at $405 \mathrm{~nm}$ was measured. End-point titer was calculated by subtracting the average negative OD from the average sample OD, with a value above 0.4999 , considered positive and was reported as the reciprocal of the highest dilution providing a positive value.

\subsection{Opsonophagocytic Killing Assay. In Vitro Killing of Staphylococcus aureus}

MN8 was performed as previously described $[9,26]$. Controls included mAb F429 against alginate with human phagocytic cells and 10\% bovine complement, mAb F598 against PNAG and 10\% bovine complement without phagocytic cells, mAb F598 and phagocytic cells without bovine complement, and mAb F598 with phagocytic cells and complement. Percent killing was calculated as the ratio of the number of colony-forming units (CFU) in the tubes containing bacteria as well as the complement, phagocytic cell, and post-immunization sera to the number of $\mathrm{CFU}$ in the tubes containing bacteria, complement, phagocytic cell, and pre-immunization sera. 


\subsection{Challenge with B. bovis Texas T2Bo Stabilate}

Twenty-seven days after the last immunization, the calves were challenged via the intravenous injection of $10^{7}$ B. bovis-infected erythrocytes in $5 \mathrm{~mL}$ of diluent (Puck's Saline $\mathrm{G}$ with $10 \%$ normal bovine serum). Rectal temperature, appetite, attitude, packed cell volume (PCV), and parasitemia, were monitored daily via PCR beginning on day 5 postinfection. When a rectal body temperature $>40.3{ }^{\circ} \mathrm{C}$ [27] was measured, the calves were administered flunixin meglumine (1.1-2.2 mg/kg; Merck Animal Health, Kenilworth, NJ, USA). When the animals were off-feed or lethargic, oral electrolytes were offered twice a day in order to avoid/combat dehydration (due to pyrexia and decreased water intake) and to provide some energy and electrolyte intake (due to anorexia) as well as to help determine the overall status of the animals. Reluctance or refusal to take the electrolytes indicated that animals were experiencing the worsening of acute disease. The calves were euthanized if the body temperature remained $>40.3{ }^{\circ} \mathrm{C}$ for 3 days and/or if the PCV dropped below $14 \%$ and/or if inappetence and lethargy were progressing.

\subsection{PCR to Detect B. bovis Post-Challenge}

Nested PCR was conducted as previously described in order to detect rap-1 $[23,24]$. Quantitative PCR was used to detect the merozoite surface antigen 1 gene (msa-1) and was conducted essentially as described; however, the final reaction volume was $25 \mu \mathrm{L}$ [28,29].

\subsection{Statistical Analysis}

PNAG antibody titers were analyzed using a mixed model with the fixed effects of treatment and the day of sampling, and animal was used as the random variable. The parameters for infection in the vaccinated and control groups of calves were compared with Student's $t$-test (peak decrease in packed cell volume, days to develop fever, peak parasite copy numbers) and the Mann-Whitney rank sum test (days to detection of parasitemia).

\subsection{Ethics Statement}

This study was approved by the Institutional Animal Care and Use Protocol Committees of the University of Idaho, Moscow, Idaho (protocol \#2018-16), in accordance with institutional guidelines based on the U.S. National Institutes of Health (NIH) Guide for the Care and Use of Laboratory Animals.

\section{Results}

\subsection{Expression of PNAG on Babesia parasites}

Immunofluorescence assays using the PNAG-specific mAb F598 demonstrated that PNAG was present on the blood stages of the bovine Babesia spp., B. bovis, and B. bigemina; the zoonotic pathogen, $B$. divergens; and the human parasites $B$. microti and Babesia WA1 (Figure 1, $\alpha$ PNAG, green). In contrast, isotype control mAb F429 showed no reactivity with the Babesia parasites (Supplemental Figure S1). The co-localization of the anti-PNAG antibodies with Babesia was determined by DNA labeling using SYTO 83 (Figure 1, DNA stain, red). Merged images showed the specific reactivity of mAb F598 to the Babesia parasites (Figure 1, Merge, yellow).

\subsection{Characterization of PNAG-Specific Antibodies in Immunized Calves}

All three animals who had been immunized with $5 \mathrm{GlcNH}_{2}-\mathrm{TT}$ developed specific antibodies against PNAG, which were measured using ELISA, while the control animals did not ( $p<0.001$, Figure 2). Immunofluoresence assays using pre-immune sera (Figure 3A,B, Pre) and sera from cattle in the adjuvant group (Figure 3A, Post) showed no antibody reactivity against PNAG on the $B$. bovis Texas strain. In contrast, sera from the immunized group recognized PNAG on the B. bovis Texas strain (Figure 3B, Post). Immunization also induced antibodies with opsonophagocytic killing activity against $S$. aureus (Figure 4). 


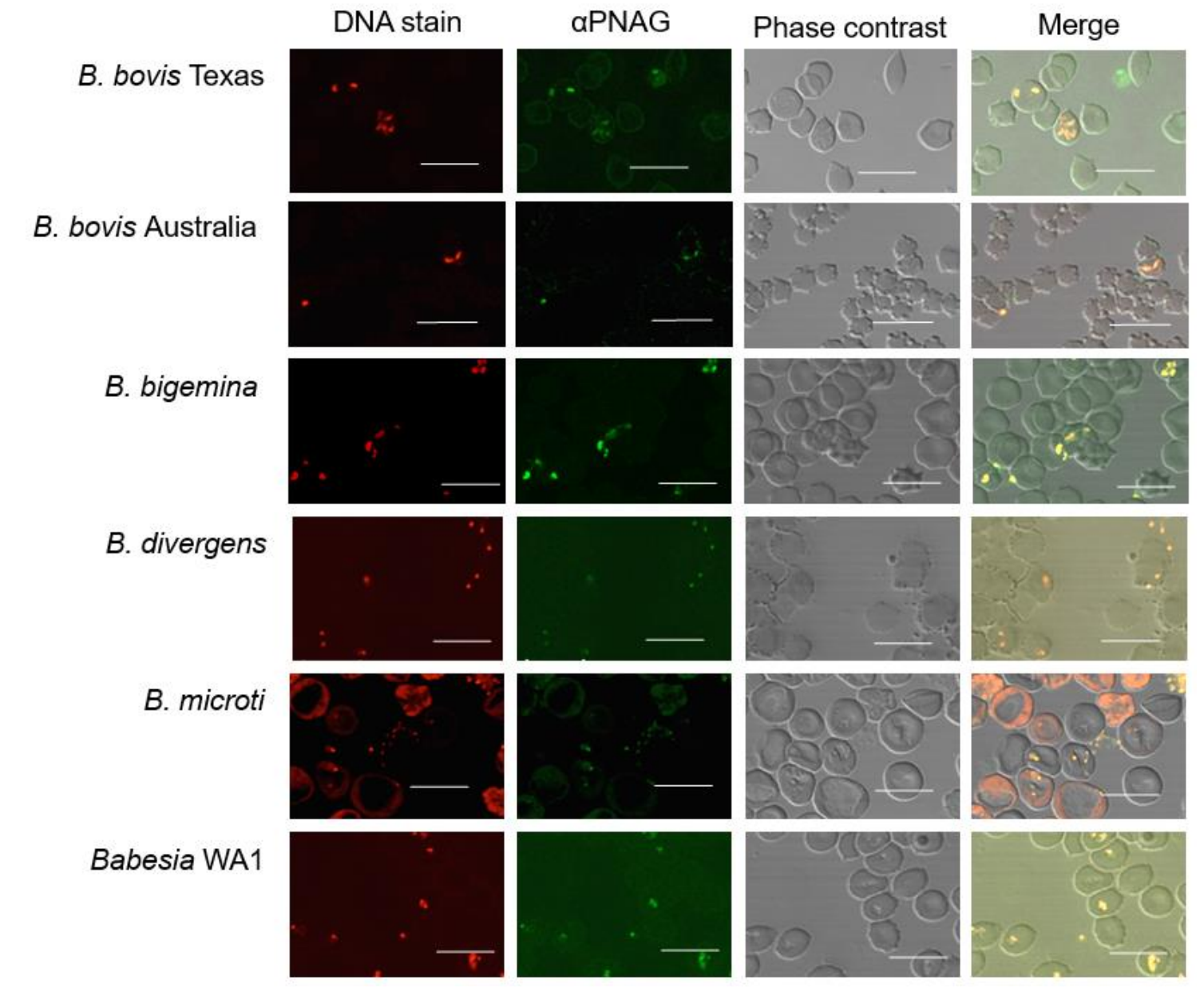

Figure 1. Conservation of poly-N-acetyl-glucosamine (PNAG) in Babesia spp. demonstrated using direct immunofluorescence on infected blood smears. DNA stain = Babesia DNA detected using SYTO 83; $\alpha$ PNAG = Alexafluor 488-conjugated anti-PNAG monoclonal antibody; phase contrast = light micrograph; merge = merged image of panels DNA stain and $\alpha$ PNAG columns. White bars $=10 \mu \mathrm{m}$.

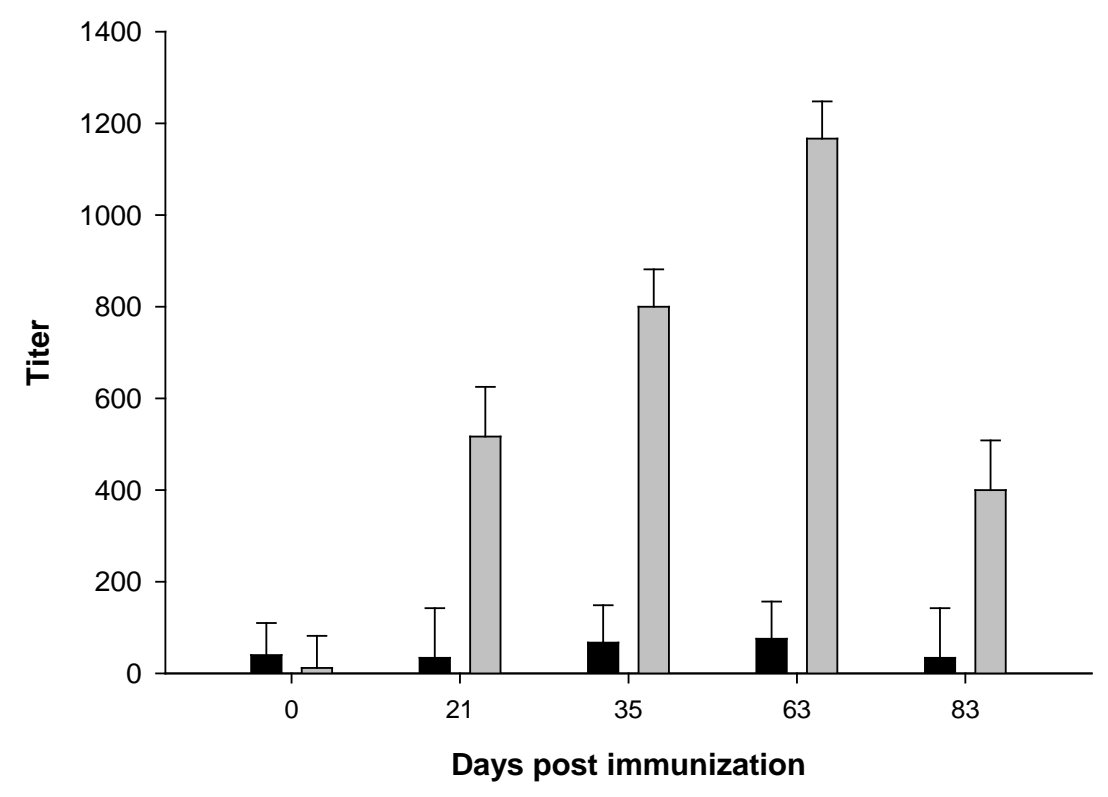

Figure 2. Stimulation of PNAG-specific antibodies following immunization with $5 \mathrm{GlcNH}_{2}-\mathrm{TT}_{\mathrm{C}}$ plus adjuvant (light bars) vs. adjuvant only group (dark bars). $p<0.001$, ANOVA. 

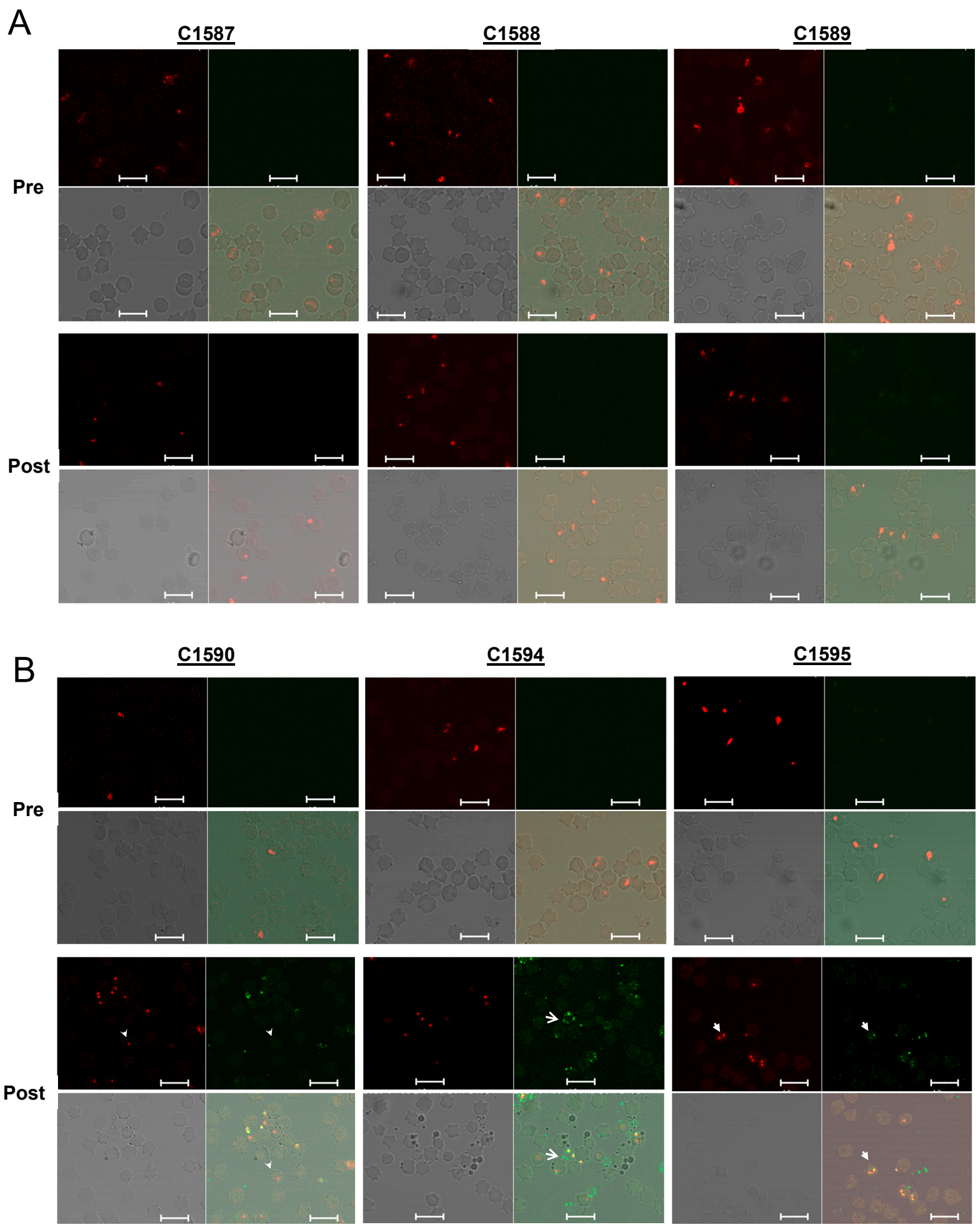

Figure 3. Recognition of $B$. bovis blood stages by sera from immunized cattle demonstrated using indirect immunofluorescence. Each set of four panels arranged starting at upper left going clockwise are SYTO 83 DNA stain, calf serum, merged image, phase contrast. (A) Reactivity of sera from control calves with thin blood smears of B. bovis-infected red blood cells. (B) Reactivity of sera from $5 \mathrm{GlcNH}_{2}$-TT-immunized calves with thin blood smears of B. bovis-infected red blood cells. Arrow heads in C1590 Post indicate parasite without serum reactivity. Arrows in C1594 Post indicate serum reactivity without DNA staining. Closed arrows in C1595 indicate co-localization of DNA stain and serum reactivity. Pre = Pre-immune sera; Post $=$ sera $72 \mathrm{~d}$ post-immunization. White bars are $10 \mu \mathrm{m}$. 


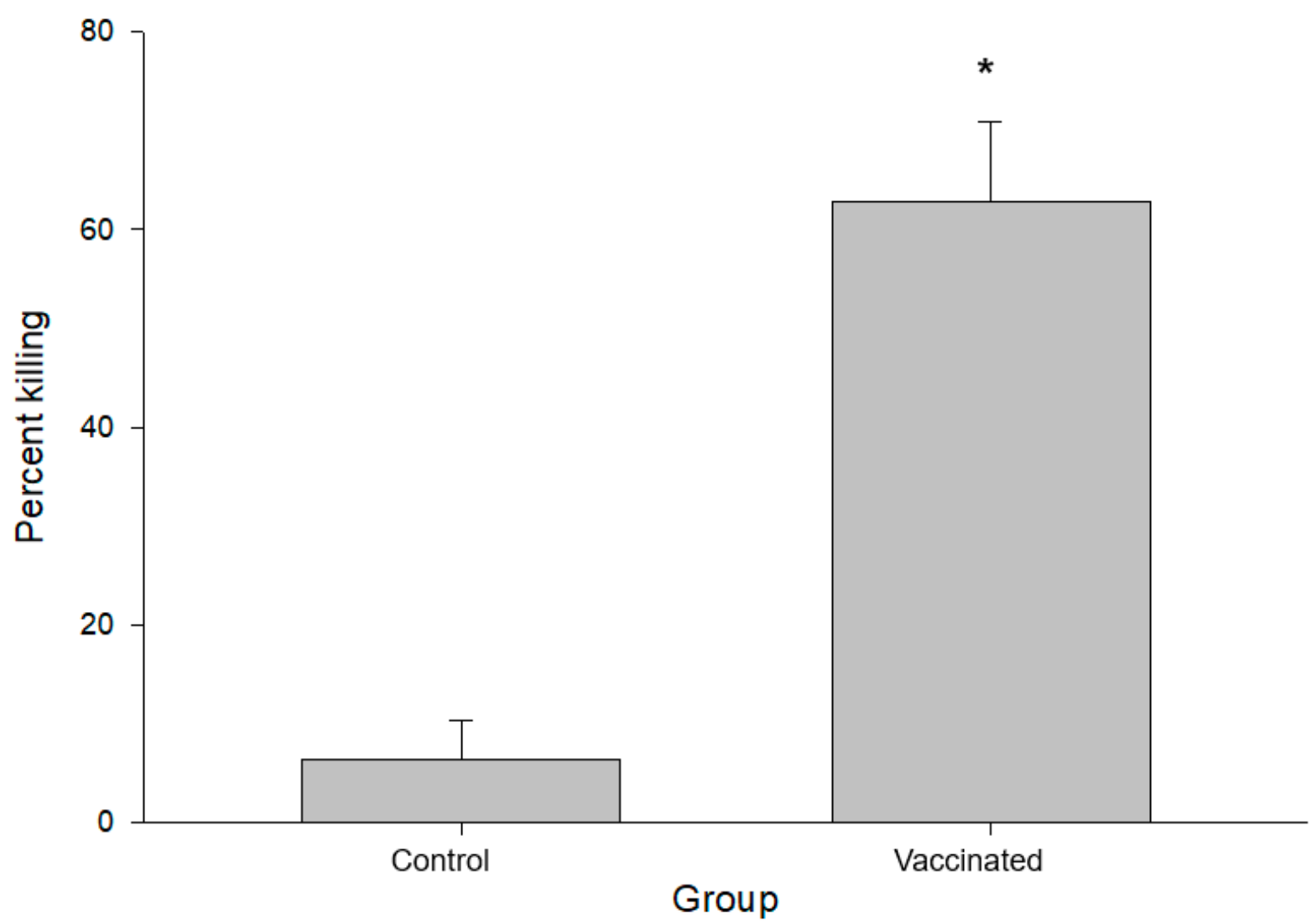

Figure 4. Opsonophagocytic killing of Staphylococcus aureus MN8 by sera 35d post vaccination. * $p<0.001$, Student's $t$-test.

\subsection{Development of Babesiosis in Immunized Calves}

All of the animals in both the vaccinated and control groups suffered severe clinical signs of bovine babesiosis regardless of the antibody titer or killing ability of the antibodies (Tables 1 and S1-S3). Severe disease caused by B. bovis is the result of cerebral babesiosis, in which parasitized erythrocytes are sequestered in the capillary vessels of the brain. Histological evaluation of the brain from all of the calves revealed high levels of infected $B$. bovis erythrocytes in the capillaries of the cerebrum and midbrain, indicating that the antibody to PNAG did not affect the sequestration of the B. bovis-infected erythrocytes. Representative histological images from a control calf (Figure 5 Control) and vaccinated calf are shown (Figure 5 Immunized).

Table 1. Development of babesiosis in calves inoculated with B. bovis.

\begin{tabular}{|c|c|c|c|}
\hline & Adjuvant ${ }^{1}$ & PNAG $^{2}$ & Test, $p$ Value \\
\hline \multicolumn{4}{|l|}{ Parameter } \\
\hline $\begin{array}{l}\text { Median days to detect } \\
\text { parasitemia }\end{array}$ & $6 \mathrm{DPI}^{3}$ & $7 \mathrm{DPI}$ & $\begin{array}{c}\text { Mann-Whitney rank sum test, } \\
\qquad p=0.2\end{array}$ \\
\hline Mean peak decrease in $\mathrm{PCV}^{4}$ & $37.76 \%$ & $45.43 \%$ & Student's $t$-test, $p=0.537$ \\
\hline $\begin{array}{l}\text { Mean days to develop } \\
\text { fever } \geq 39.4^{\circ} \mathrm{C}\end{array}$ & 7.7 & 8.3 & Student's $t$-test, $p=0.519$ \\
\hline $\begin{array}{c}\text { Mean peak parasite copy } \\
\text { numbers } \pm \text { SD }\end{array}$ & $1.82 \times 10^{6} \pm 2.26 \times 10^{6}$ & $8.64 \times 10^{5} \pm 2.26 \times 10^{5}$ & Student's $t$-test, $p=0.508$ \\
\hline
\end{tabular}

${ }^{1}$ Adjuvant $=$ animals immunized with adjuvant only, ${ }^{2}$ PNAG $=$ animals immunized with $5 \mathrm{GlcNH}_{2}-\mathrm{TT} .{ }^{3}$ DPI $=$ days post inoculation with B. bovis, ${ }^{4} \mathrm{PCV}=$ packed red cell volume, $\mathrm{SD}=$ standard deviation. 

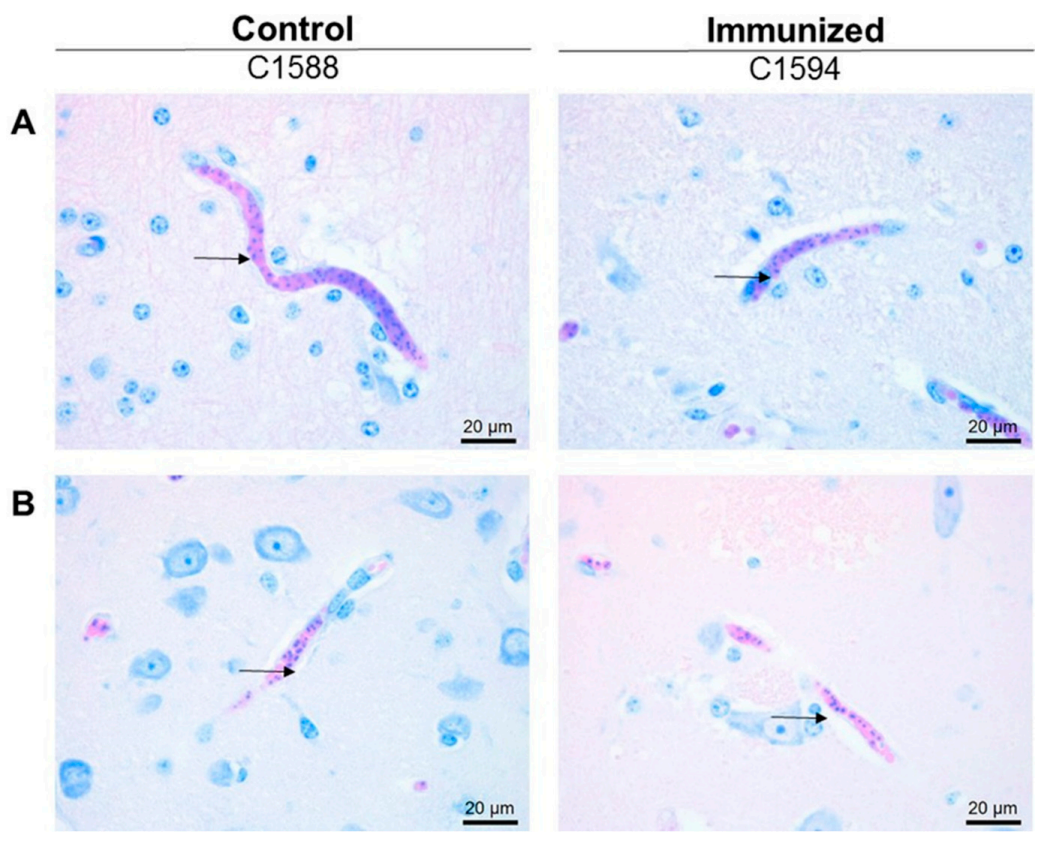

Figure 5. Detection of B. bovis-infected erythrocytes in the capillaries of the (A) cerebrum and (B) midbrain of an adjuvant-only control calf (Control) and a PNAG-immunized calf (Immunized) challenged with B. bovis. Arrows indicate B. bovis-infected erythrocytes. Images are representative of all calves.

\section{Discussion}

The immune control of $B$. bovis infection in cattle is thought to include both innate and adaptive responses $[4,30]$. In young calves who are up to about $6-10$ months of age, resistance to severe acute disease is mediated by splenic innate immune cells that also lead to adaptive responses, CD4+ T-cells, and memory B-cells that protect against disease from subsequent infections as the animal ages. This innate immune resistance allows the safe use of live vaccines in young calves. Immunologically naïve older cattle generally do not display a strong innate immune response and succumb to acute disease [4,8,30-32], which precludes the use of live vaccines in older animals.

Subunit vaccines avoid the problem of live vaccine-induced disease, and studies have looked at using recombinant proteins alone, as reviewed in [30], or recombinant proteins followed by a boost with a virus vector encoding the antigen [33] in order to stimulate protection against the clinical disease that is caused by B. bovis. Despite the stimulation of antigen-specific CD4+ T-cells and antibodies, none of the vaccine regimens resulted in protection from disease when the cattle were challenged with virulent $B$. bovis $[30,33]$, illustrating the complexity of developing vaccines against $B$. bovis [6].

Early work, most of which was focused of the role of humoral immunity against babesiosis, demonstrated that passively transferred antibodies protected the cattle against disease caused by homologous strains of B. bovis [4]. We sought to identify an antigen conserved among different strains and species of Babesia that could be used to provide a broadly protective antibody response against severe clinical disease.

Numerous studies have demonstrated the induction of protective antibody responses against bacteria by immunization with dPNAG or synthetic B-(1 $\rightarrow 6)$-linked glucosamine oligosaccharides that have been conjugated to carrier proteins (reviewed in [10]) as well as a few eukaryotic pathogens, including the apicomplexan parasite Plasmodium berghei [9]. Specifically, the anti-PNAG antibodies prevented cerebral malaria, decreased parasitemia, and significantly prolonged the survival of mice who had been infected with P. berghei [9]. Because B. bovis-infected red blood cell sequestration in brain capillaries is a prominent feature of clinical babesiosis in infected cattle, we hypothesized that antibodies to PNAG would provide protection against B. bovis, similar to what was seen in mice. 
The immunization of calves with PNAG stimulated high-titer, specific antibody responses with opsonophagocytic killing activity against a control bacterium, S. aureus MN8, which is known to express PNAG. However, despite the documented display of PNAG by the parasite, this antibody response did not protect calves who had been challenged with $B$. bovis-infected erythrocytes against the severe clinical manifestation of bovine babesiosis. All of the PNAG-immunized animals developed clinical babesiosis with parasite sequestration in brain capillaries and peripheral parasite loads that were indistinguishable from the control animals. This result differs from the results of the study by Cywes-Bentley et al. [9].

The protection mechanism that is induced by PNAG antibodies is achieved via the deposition of complement components onto the target cell(s), leading to the opsonic killing of the pathogen $[9,10,14]$. Thus, this requires babesial PNAG to be physically accessible to the antibodies. Although the blood stages of Babesia exit the erythrocytes in order to infect new red blood cells in order to perpetuate the merozoite propagation cycle, it is possible that the antigen is not surface exposed, either due to location or because it is masked by known surface proteins such as merozoite surface antigens.

Finally, the immune correlates of disease protection, including the full elucidation of the role of different T-cell subsets in the protection against bovine babesiosis, remain elusive. Interestingly, Jaramillo Ortiz et al. observed antigen-specific CD8+ T-cells in cattle who had been immunized with a live vaccine [33]. However, since B. bovis only resides in erythrocytes, it is unclear what role the CD8+ T-cells have in controlling disease. More studies examining the mechanisms of innate and acquired immune responses in calves to B. bovis infection are needed and will lead to improved vaccination strategies in the efforts to control babesiosis in cattle and to prevent economic losses for livestock producers.

\section{Conclusions}

Developing safe and effective vaccines to protect cattle from babesiosis is a top priority for animal health researchers. Identifying conserved antigens that can induce immunity against different Babesia species and strains is challenging. Poly-N-acetyl-glucosamine is a conserved surface polysaccharide that is expressed by a great diversity of organisms, including the apicomplexan parasites $P$. berghei and P. falciparum, and antibodies against PNAG provided protection from disease in a mouse malaria model. In our study, we showed that Babesia spp express PNAG, making it an attractive and potential target for a universal vaccine against babesiosis. Despite the development of anti-PNAG antibodies in calves following immunization with $5 \mathrm{GlcNH}_{2}-\mathrm{TT}$, no protection against acute babesiosis was detected. However, it was important to experimentally test the possibility that antiPNAG antibodies could provide some protection from disease, and the result of this work does not preclude testing as to whether PNAG is useful against other protozoan parasites.

Supplementary Materials: The following are available online at https: / www.mdpi.com/article/ 10.3390/pathogens10121598/s1, Figure S1: Blood smears probed with isotype control (F429) and Babesia DNA labeled with SYTO 83 (red fluorescence), Table S1: Development of babesiosis in individual calves inoculated with B. bovis, Table S2: Clinical parameters measured in calves following intravenous inoculation of T2Bo B. bovis infected erythrocyte. Table S3: Detection of T2Bo B. bovis DNA in peripheral blood following inoculation of infected erythrocytes.

Author Contributions: Conceptualization, C.C.-B., G.B.P. and M.W.U.; methodology, N.S.T.; C.C.-B.; W.C.J. and M.W.U.; formal analysis, N.S.T. and M.R.M.; investigation, N.S.T.; C.C.-B.; W.C.J. and L.M.F.; resources, G.B.P. and M.W.U.; data curation, N.S.T., G.B.P., L.M.F.; writing-original draft preparation, N.S.T.; writing—review and editing, N.S.T.; W.C.J.; G.B.P.; L.M.F.; M.R.M. and M.W.U.; visualization, N.S.T.; C.C.-B.; L.M.F.; M.R.M. and M.W.U.; supervision, G.B.P. and M.W.U.; project administration, N.S.T.; funding acquisition, G.B.P. and M.W.U. All authors have read and agreed to the published version of the manuscript.

Funding: This study was supported by USDA-ARS CRIS project number 2090-32000-039-00D and Alopexx Vaccine, LLC. The funders had no role in study design, data collection and analysis, decision to publish, or preparation of the manuscript. 
Institutional Review Board Statement: This study was approved by the Institutional Animal Care and Use Protocol Committees of the University of Idaho, Moscow, Idaho (protocol \#2018-16), in accordance with institutional guidelines based on the U.S. National Institutes of Health (NIH) Guide for the Care and Use of Laboratory Animals.

Informed Consent Statement: Not applicable.

Data Availability Statement: Not applicable.

Acknowledgments: The authors thank Nic Durfee for the technical support and James Allison and Megan Blauert for the animal care.

Conflicts of Interest: Gerald B. Pier is an inventor of intellectual properties (human monoclonal antibody to PNAG and PNAG vaccines) that are licensed by Brigham and Women's Hospital to Alopexx Vaccine, LLC, and Alopexx Pharmaceuticals, LLC, entities in which GBP also holds equity. As an inventor of intellectual properties, GBP also has the right to receive a share of licensing-related income (royalties, fees) through the Brigham and Women's Hospital from Alopexx Pharmaceuticals, LLC, and Alopexx Vaccine, LLC. GBP's interests were reviewed and are managed by the Brigham and Women's Hospital and Partners Health care in accordance with their conflict of interest policies. Colette Cywes-Bentley is an inventor of intellectual properties (use of human monoclonal antibody to PNAG and use of PNAG vaccines) that are licensed by the Brigham and Women's Hospital to Alopexx Pharmaceuticals, LLC. As an inventor of intellectual properties, CC-B also has the right to receive a share of licensing-related income (royalties, fees) through Brigham and Women's Hospital from Alopexx Pharmaceuticals, LLC.

$\begin{array}{ll}\text { Abbreviations } \\ \text { PNAG } & \text { poly-N-acetylglucosamine } \\ \text { dPNAG } & \text { deactylated poly-N-acetylglucosamine } \\ \text { TT } & \text { tetanus toxoid } \\ \text { BSA } & \text { bovine serum albumin } \\ \text { PCV } & \text { packed cell volume }\end{array}$

\section{References}

1. Suarez, C.E.; Noh, S. Emerging perspectives in the research of bovine babesiosis and anaplasmosis. Vet. Parasitol. 2011, 180, 109-125. [CrossRef]

2. Suarez, C.E.; Alzan, H.F.; Silva, M.G.; Rathinasamy, V.; Poole, W.A.; Cooke, B.M. Unravelling the cellular and molecular pathogenesis of bovine babesiosis: Is the sky the limit? Int. J. Parasitol. 2019, 49, 183-197. [CrossRef]

3. Brown, W.C.; Palmer, G.H. Designing blood-stage vaccines against Babesia bovis and B. bigemina. Parasitol. Today 1999, 15, 275-281. [CrossRef]

4. Bock, R.; Jackson, L.; de Vos, A.; Jorgensen, W. Babesiosis of cattle. Parasitology 2004, 129, S247-S269. [CrossRef] [PubMed]

5. Rodriguez-Vivas, R.I.; Jonsson, N.N.; Bhushan, C. Strategies for the control of Rhipicephalus microplus ticks in a world of conventional acaricide and macrocyclic lactone resistance. Parasitol. Res. 2018, 117, 3-29. [CrossRef]

6. Florin-Christensen, M.; Suarez, C.E.; Rodriguez, A.E.; Flores, D.A.; Schnittger, L. Vaccines against bovine babesiosis: Where we are now and possible roads ahead. Parasitology 2014, 1-30. [CrossRef]

7. Shkap, V.; Leibovitz, B.; Krigel, Y.; Hammerschlag, J.; Marcovics, A.; Fish, L.; Molad, T.; Savitsky, I.; Mazuz, M. Vaccination of older Bos taurus bulls against bovine babesiosis. Vet. Parasitol. 2005, 129, 235-242. [CrossRef] [PubMed]

8. Trueman, K.F.; Blight, G.W. The effect of age on resistance of cattle to Babesia bovis. Aust. Vet. J. 1978, 54, 301-305. [CrossRef] [PubMed]

9. Cywes-Bentley, C.; Skurnik, D.; Zaidi, T.; Roux, D.; Deoliveira, R.B.; Garrett, W.S.; Lu, X.; O’Malley, J.; Kinzel, K.; Zaidi, T.; et al. Antibody to a conserved antigenic target is protective against diverse prokaryotic and eukaryotic pathogens. Proc. Natl. Acad. Sci. USA 2013, 110, E2209-E2218. [CrossRef]

10. Skurnik, D.; Cywes-Bentley, C.; Pier, G.B. The exceptionally broad-based potential of active and passive vaccination targeting the conserved microbial surface polysaccharide PNAG. Expert Rev. Vaccines 2016, 15, 1041-1053. [CrossRef]

11. Kelly-Quintos, C.; Cavacini, L.A.; Posner, M.R.; Goldmann, D.; Pier, G.B. Characterization of the opsonic and protective activity against Staphylococcus aureus of fully human monoclonal antibodies specific for the bacterial surface polysaccharide poly-N-acetylglucosamine. Infect. Immun. 2006, 74, 2742-2750. [CrossRef]

12. Skurnik, D.; Kropec, A.; Roux, D.; Theilacker, C.; Huebner, J.; Pier, G.B. Natural antibodies in normal human serum inhibit Staphylococcus aureus capsular polysaccharide vaccine efficacy. Clin. Infect. Dis. Off. Publ. Infect. Dis. Soc. Am. 2012, 55, 1188-1197. [CrossRef] 
13. Skurnik, D.; Merighi, M.; Grout, M.; Gadjeva, M.; Maira-Litran, T.; Ericsson, M.; Goldmann, D.A.; Huang, S.S.; Datta, R.; Lee, J.C.; et al. Animal and human antibodies to distinct Staphylococcus aureus antigens mutually neutralize opsonic killing and protection in mice. J. Clin. Investig. 2010, 120, 3220-3233. [CrossRef]

14. Cywes-Bentley, C.; Rocha, J.N.; Bordin, A.I.; Vinacur, M.; Rehman, S.; Zaidi, T.S.; Meyer, M.; Anthony, S.; Lambert, M.; Vlock, D.R.; et al. Antibody to Poly-N-acetyl glucosamine provides protection against intracellular pathogens: Mechanism of action and validation in horse foals challenged with Rhodococcus equi. PLoS. Pathog. 2018, 14, e1007160. [CrossRef]

15. Goff, W.L.; Wagner, G.G.; Craig, T.M.; Long, R.F. The bovine immune response to tick-derived Babesia bovis infection: Serological studies of isolated immunoglobulins. Vet. Parasitol. 1982, 11, 109-120. [CrossRef]

16. Goff, W.L.; Johnson, W.C.; Cluff, C.W. Babesia bovis immunity. In vitro and in vivo evidence for IL-10 regulation of IFN-gamma and iNOS. Ann. N. Y. Acad. Sci. 1998, 849, 161-180. [CrossRef] [PubMed]

17. Suarez, C.E.; Palmer, G.H.; Jasmer, D.P.; Hines, S.A.; Perryman, L.E.; McElwain, T.F. Characterization of the gene encoding a 60-kilodalton Babesia bovis merozoite protein with conserved and surface exposed epitopes. Mol. Biochem. Parasitol. 1991, 46, 45-52. [CrossRef]

18. Bohaliga, G.A.R.; Johnson, W.C.; Taus, N.S.; Hussein, H.E.; Bastos, R.G.; Suarez, C.E.; O'Connor, R.; Ueti, M.W. Identification of a putative methyltransferase gene of Babesia bigemina as a novel molecular biomarker uniquely expressed in parasite tick stages. Parasites Vectors 2018, 11, 480. [CrossRef]

19. Goff, W.L.; Jessup, D.A.; Waldrup, K.A.; Thomford, J.W.; Conrad, P.A.; Boyce, W.M.; Gorham, J.R.; Wagner, G.G. The isolation and partial characterization of a Babesia sp. from desert bighorn sheep (Ovis canadensis nelsoni). J. Eukaryot. Microbiol. 1993, 40, 237-243. [CrossRef]

20. Holman, P.J.; Spencer, A.M.; Telford, S.R., 3rd; Goethert, H.K.; Allen, A.J.; Knowles, D.P.; Goff, W.L. Comparative infectivity of Babesia divergens and a zoonotic Babesia divergens-like parasite in cattle. Am. J. Trop. Med. Hyg. 2005, 73, 865-870. [CrossRef]

21. Herwaldt, B.; Persing, D.H.; Précigout, E.A.; Goff, W.L.; Mathiesen, D.A.; Taylor, P.W.; Eberhard, M.L.; Gorenflot, A.F. A fatal case of babesiosis in Missouri: Identification of another piroplasm that infects humans. Ann. Intern. Med. 1996, 124, 643-650. [CrossRef] [PubMed]

22. Pier, G.B.; Boyer, D.; Preston, M.; Coleman, F.T.; Llosa, N.; Mueschenborn-Koglin, S.; Theilacker, C.; Goldenberg, H.; Uchin, J.; Priebe, G.P.; et al. Human monoclonal antibodies to Pseudomonas aeruginosa alginate that protect against infection by both mucoid and nonmucoid strains. J. Immunol. 2004, 173, 5671-5678. [CrossRef]

23. Goff, W.L.; Molloy, J.B.; Johnson, W.C.; Suarez, C.E.; Pino, I.; Rhalem, A.; Sahibi, H.; Ceci, L.; Carelli, G.; Adams, D.S.; et al. Validation of a competitive enzyme-linked immunosorbent assay for detection of antibodies against Babesia bovis. Clin. Vaccine Immunol. CVI 2006, 13, 1212-1216. [CrossRef]

24. Suarez, C.E.; Laughery, J.M.; Schneider, D.A.; Sondgeroth, K.S.; McElwain, T.F. Acute and persistent infection by a transfected Mo7 strain of Babesia bovis. Mol. Biochem. Parasitol. 2012, 185, 52-57. [CrossRef] [PubMed]

25. Choi, A.H.; Slamti, L.; Avci, F.Y.; Pier, G.B.; Maira-Litrán, T. The pgaABCD locus of Acinetobacter baumannii encodes the production of poly-beta-1-6-N-acetylglucosamine, which is critical for biofilm formation. J. Bacteriol. 2009, 191, 5953-5963. [CrossRef] [PubMed]

26. Maira-Litran, T.; Kropec, A.; Goldmann, D.A.; Pier, G.B. Comparative opsonic and protective activities of Staphylococcus aureus conjugate vaccines containing native or deacetylated Staphylococcal Poly-N-acetyl-beta-(1-6)-glucosamine. Infect. Immun. 2005, 73, 6752-6762. [CrossRef] [PubMed]

27. Merck Veterinary Manual. Available online: https://merckvetmanual.com/special-subjects/reference-guides/normal-rectaltemperature-ranges (accessed on 30 November 2021).

28. Bastos, R.G.; Ueti, M.W.; Guerrero, F.D.; Knowles, D.P.; Scoles, G.A. Silencing of a putative immunophilin gene in the cattle tick Rhipicephalus (Boophilus) microplus increases the infection rate of Babesia bovis in larval progeny. Parasites Vectors $2009,2,57$. [CrossRef] [PubMed]

29. Howell, J.M.; Ueti, M.W.; Palmer, G.H.; Scoles, G.A.; Knowles, D.P. Transovarial transmission efficiency of Babesia bovis tick stages acquired by Rhipicephalus (Boophilus) microplus during acute infection. J. Clin. Microbiol. 2007, 45, 426-431. [CrossRef] [PubMed]

30. Brown, W.C.; Norimine, J.; Knowles, D.P.; Goff, W.L. Immune control of Babesia bovis infection. Vet. Parasitol. 2006, 138 , 75-87. [CrossRef]

31. Goff, W.L.; Bastos, R.G.; Brown, W.C.; Johnson, W.C.; Schneider, D.A. The bovine spleen: Interactions among splenic cell populations in the innate immunologic control of hemoparasitic infections. Vet. Immunol. Immunopathol. 2010, 138, 1-14. [CrossRef] [PubMed]

32. Goff, W.L.; Johnson, W.C.; Parish, S.M.; Barrington, G.M.; Tuo, W.; Valdez, R.A. The age-related immunity in cattle to Babesia bovis infection involves the rapid induction of interleukin-12, interferon-gamma and inducible nitric oxide synthase mRNA expression in the spleen. Parasite Immunol. 2001, 23, 463-471. [CrossRef]

33. Jaramillo, O.J.M.; Paoletta, M.S.; Gravisaco, M.J.; López, A.L.S.; Montenegro, V.N.; de la Fournière, S.A.M.; Valenzano, M.N.; Guillemi, E.C.; Valentini, B.; Echaide, I.; et al. Immunisation of cattle against Babesia bovis combining a multi-epitope modified vaccinia Ankara virus and a recombinant protein induce strong Th1 cell responses but fails to trigger neutralising antibodies required for protection. Ticks Tick-Borne Dis. 2019, 10, 101270. [CrossRef] [PubMed] 